\title{
Nanofluid Convective Heat Transfer Enhancement Elliptical Tube inside Circular Tube under Turbulent Flow
}

\author{
Suad Hassan Danook ${ }^{1}$ (), Qusay Kamel Jasim ${ }^{2}$ and Adnan Mohammed Hussein ${ }^{2, *}$ \\ 1 Kirkuk Technical College, Northern Technical University, Mosul 41002, Iraq; talebshebab@yahoo.com \\ 2 Al-Haweeja Institute, Northern Technical University, Mosul 41002, Iraq; kamelqusay44@gmail.com \\ * Correspondence: adnanphd2012@gmail.com
}

Received: 22 September 2018; Accepted: 23 November 2018; Published: 6 December 2018

\begin{abstract}
Heat transfer enhancement employing an elliptical tube inside a circular tube to increase the heat transfer rate without increasing in pressure drop is investigated. The flow rate inside the narrow is in the range of Reynolds number 10,000 to 100,000. Commercial software is used to solve the governing equations (continuity, momentum, and energy) by adopting a finite volume method (FVM). The electrical heater is connected around the circular tube to apply uniform heat flux $\left(3000 \mathrm{~W} / \mathrm{m}^{2}\right)$ as a boundary condition. The volume concentrations are in the range of $0.25 \%$ to $1 \%$ with different $\mathrm{TiO}_{2}$ nanoparticle diameters in the range of $27 \mathrm{~nm}$ to $50 \mathrm{~nm}$ dispersed in water. The results indicate that the elliptical annulus tube can enhance heat transfer and friction factor by approximately $19 \%$ and $6 \%$ than the circular tube respectively. Results show that the heat transfer enhancement is significantly increasing as the volume concentrations increase and the nanoparticles size diameter decrease.
\end{abstract}

Keywords: nanofluid; CFD; elliptical tube; heat exchanger; FLUENT

\section{Introduction}

Very small particles suspension in saturated liquids (water, ethylene glycol, engine oil) is defined as nanofluids may constitute a very interesting alternative for advanced thermal applications. It has been found that important heat transfer enhancement may be achieved while using nanofluids compared to the use of conventional fluids; furthermore, some oxide nanoparticles exhibit an excellent dispersion property in traditional cooling liquids [1].

Turbulent forced convection heat transfer of water and nanofluid inside tube under single phase approach was carried out by the authors of References [2-6]. Pak and Cho [7] were investigated the effect of two different metallic oxide particles, titanium dioxide and alumina with mean diameters of 27 and $13 \mathrm{~nm}$, respectively on base fluid (water) experimentally. Results showed that heat transfer enhancement with nanofluids have better than base fluid. A theoretical model was proposed by Sharma et al. [8] to predict friction and heat transfer coefficients for different nanofluids containing $\mathrm{Cu}, \mathrm{CuO}, \mathrm{TiO}_{2}, \mathrm{SiC}, \mathrm{ZrO}_{2}$, and $\mathrm{Al}_{2} \mathrm{O}_{3}$ nanoparticles of different sizes, concentration, and temperatures dispersed in water. Results showed $6 \%$ deviation between theoretical and experimental data.

The CFD modeling of heat transfer enhancement of $\mathrm{Al}_{2} \mathrm{O}_{3}$ nanofluid using low volume fraction under turbulent pipe flow with constant wall temperature has been studied by Kumar [9]. Nusselt number $(\mathrm{Nu})$ and friction factor have been predicted for the low volume fractions (i.e., $0.02 \%, 0.1 \%$ and $0.5 \%$ ). Numerical study of turbulent forced convection flow of alumina nanofluid through the circular tube was subjected by Bianco [10]. Results showed that Heat transfer increased with the particle volume concentration and Reynolds number. Experimental study of turbulent forced convection heat transfer through pipe employing twisted tape with and without $\mathrm{Al}_{2} \mathrm{O}_{3}$-water nanofluid was conducted 
by Sundar and Sharma [11]. The generalized correlation has been developed for the estimation of the Nusselt number and friction factor of pipe with and without inserts.

A wide variety of practical and industrial applications of forced convection in an elliptical tube between two horizontal cylinders such as heat exchangers, heating processes, power generation, chemical processes, microelectronics, and cooling processes have been led to interest this type of study [12-16].

Duangthongsuk and Wongwises [17] found the heat transfer coefficient and friction factor of the nanofluid $\mathrm{TiO}_{2}$-water flowing in a horizontal double tube counter-flow heat exchanger under turbulent flow conditions. Results showed that the heat transfer coefficient of nanofluid is higher than that of the base fluid. Forced convection turbulent flow of $\mathrm{Al}_{2} \mathrm{O}_{3}$-water nanofluid inside an annular tube with a variable wall temperature was investigated experimentally by Prajapati [18]. Results showed the enhancement of heat transfer due to the nanoparticle dispersion in the base fluid. The forced convection flow between two corrugated cylinders was studied by Kittur [19]. The results found friction factor and heat transfer on the boundaries increased by $20 \%$.

Horizontal double-tube heat exchanger counter turbulent flow was studied numerically by Bozorgan [20]. $\mathrm{Al}_{2} \mathrm{O}_{3}$-water nanofluid of $7 \mathrm{~nm}$ with volume concentrations up to $2 \%$ are selected to use as a coolant. Results showed that the pressure drop of nanofluid is slightly higher than water and increases with an increase of volume concentrations. Forced convection flow of nanofluids of $\mathrm{TiO}_{2}$-water in a double-tube counter flow heat exchanger using CFD simulation FLUENT software has been investigated by Demir [21]. A double tube coaxial heat exchanger heated by solar energy using Aluminum oxide nanofluid presented experimentally and numerically by Luciu [22]. Results showed that nanofluids have a higher performance of heat transfer than base fluid. The lid driven semi annulus enclosure force convection heat transfer was investigated for non-uniform magnetic field with $\mathrm{Fe}_{3} \mathrm{O}_{4}$ nanoparticles suspended in water [23]. The finite element method with control volume has been adopting to solve the governing equations. The results were indicated that Reynolds number and Nusselt number have direct relationship and nanofluid volume concentrations. The second law of thermodynamics analysis has been applied to an electrically conducting incompressible nanofluid fluid flowing over a porous rotating disk [24]. Von Karman transformations have been adopted to the governing equations transformation into a nonlinear differential equations system. The velocity profiles in tangential, axial, and radial directions, averaged entropy generation number, temperature distribution, and Bejan number were evaluated. It was observed that there is a good agreement between the obtained results of the present study and those of previously in the literature.

In this work, CFD simulation by FLUENT software is used to predict friction factor and Nusselt number with turbulent forced convection of $\mathrm{TiO}_{2}$-water nanofluid through a narrow between elliptical and circular tubes under constant heat flux. Furthermore, comparison of CFD results with experimental data available in the literature is conducted to be validated.

\section{Theoretical Analysis}

\subsection{Physical Model}

The cylindrical geometry coordinate of the problem undertaken has been shown in Figure 1a, Dimensions of an elliptical tube are major and minor diameter ( $a=27 \mathrm{~mm}$ and $b=9 \mathrm{~mm}$ ), the length (L) and hydraulic diameter $\left(D_{h}\right)$ of the elliptical tube are $1000 \mathrm{~mm}$ and $24 \mathrm{~mm}$.

Reynolds number has been calculated regarded to the hydraulic diameter $\left(D_{h}\right)$ as:

$$
\begin{gathered}
D_{h}=4 \times \text { Area } / \text { Perimeter } \\
D_{e f f}=D_{o}-D_{h}
\end{gathered}
$$

where $D_{h}=$ hydraulic diameter of the elliptical tube, Area $=\frac{\pi \times a \times b}{4}$ and Perimeter $=\pi \sqrt{\frac{a^{2}+b^{2}}{2}}$ and $\left(D_{\text {eff }}\right)$ the effective diameter of heat exchanger, $D_{o}=$ diameter of circular tube. 
Reynolds number $(R e)$ is:

$$
R e=\frac{\rho_{n f} \times D_{h} \times u}{\mu_{n f}}
$$

It was assumed to be two dimensional, steady, incompressible and Newtonian turbulent fluid flow, constant thermophysical properties of nanofluid, no effect of gravity and heat conduction in the axial direction and wall thickness of tubes are neglected.

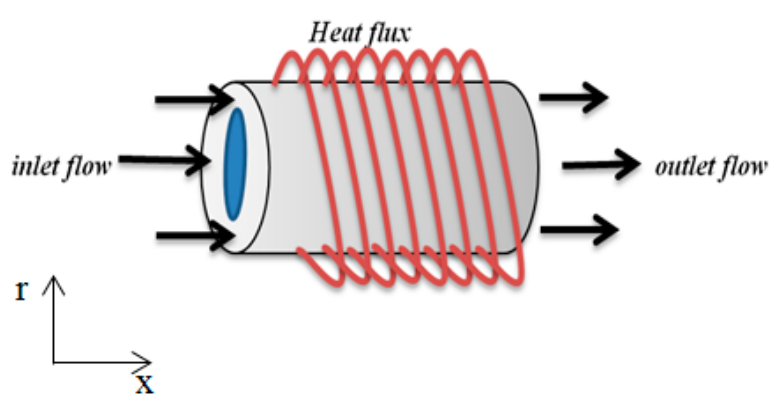

(a)

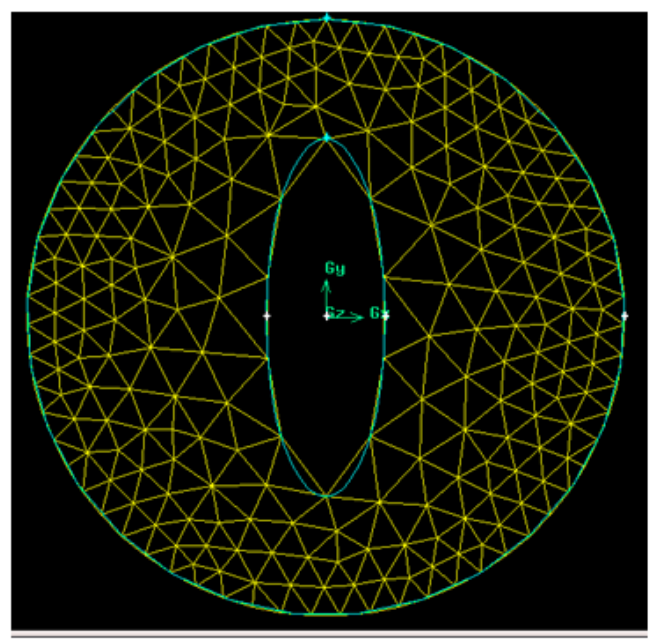

(b)

Figure 1. Geometrical problem. (a) Schematic of problem undertaken; (b) mesh generated by GAMBIT.

\subsection{Governing Equations}

Infinitesimal (less than $100 \mathrm{~nm}$ ) solid particles are considered to be able using a single phase approach, so a single phase approach is adopted for nanofluid modeling. The thermal properties of nanofluid are estimated by the equations below [25]:

$$
\begin{gathered}
\rho_{n f}=\left(\frac{\varphi}{100}\right) \rho_{p}+\left(1-\frac{\varphi}{100}\right) \rho_{f} \\
C_{n f}=\frac{\frac{\varphi}{100}(\rho C)_{p}+\left(1-\frac{\varphi}{100}\right)(\rho C)_{f}}{\rho_{n f}} \\
k_{r}=\frac{k_{n f}}{k_{f}}=\left\{\begin{array}{c}
0.8938\left(1+\frac{\varphi}{100}\right)^{1.37}\left(1+\frac{T_{n f}}{70}\right)^{0.2777}\left(1+\frac{d_{p}}{150}\right)^{-0.0336}\left(\frac{\alpha_{p}}{\alpha_{f}}\right)^{0.01737} \\
\mu_{r}=\frac{\mu_{n f}}{\mu_{f}}=\left(1+\frac{\varphi}{100}\right)^{11.3}\left(1+\frac{T_{n f}}{70}\right)^{-0.038}\left(1+\frac{d_{p}}{170}\right)^{-0.061}
\end{array}\right.
\end{gathered}
$$

where $\rho, C, k$ and $\mu$ are density, specific heat capacity, thermal conductivity and viscosity respectively, but subscripts $n f, f$, and $p$ are represented nanofluid, fluid and solid properties. On the other hand, the thermal properties of solid particles are $k_{p}=8.4 \mathrm{~W} / \mathrm{m}^{\circ} \mathrm{C}, \rho_{p}=4175 \mathrm{~kg} / \mathrm{m}^{3}, C_{p}=692 \mathrm{~J} /(\mathrm{kg} \cdot \mathrm{K})$ [25].

\subsection{Assumptions}

The velocity of fluid at all solid-fluid boundaries is equal value due to no-slip condition. The heat fluxes are taken at outer wall to be constant by electrical heater. Nanofluid is considered as Newtonian fluid, incompressible flow, no chemical reactions, dilute mixture, negligible viscous dissipation, negligible radiation, fully developed flow, and local thermal equilibrium between the nanoparticles and base fluid. 
For all these assumptions the dimensional continuity, momentum and energy equations for steady state mean conditions are as following [24]:

$$
\begin{gathered}
\frac{\partial u}{\partial x}+\frac{1}{r} \frac{\partial}{\partial r}\left(r \rho_{n f} u\right)=0 \\
u \frac{\partial u}{\partial x}+v \frac{\partial}{\partial r}\left(\rho_{n f} u\right)=-\frac{\partial P}{\partial x}+\frac{1}{r} \frac{\partial}{\partial r}\left[r\left(v+\varepsilon_{H}\right) \frac{\partial u}{\partial r}\right] \\
\frac{1}{r} \frac{\partial}{\partial r}(\rho u T)=\frac{1}{r} \frac{\partial}{\partial r}\left[r\left(\alpha+\varepsilon_{H}\right) \frac{\partial T}{\partial r}\right]+\frac{1}{r^{2}} \frac{\partial}{\partial x}\left\{\frac{k_{n f}}{C_{p}} \frac{\partial T}{\partial x}\right\}
\end{gathered}
$$

A high Reynolds number was taken as an input parameter, pressure treatment was adopted SIMPLE scheme and turbulent viscous $k-\varepsilon$ model was employed. The converged solutions were considered for residuals lower than $10^{-6}$ for all the governing equations. The results of simulation for nanofluid were compared to the equations of Blasius (Equation (10)) for friction factor and Dittus Boelter Equation (Equation (11)) for Nusselt number as:

$$
\begin{gathered}
f=\frac{0.316}{R e^{0.25}} \\
N u=\frac{h_{f}}{k_{f}} D_{e f f}=0.023 R e^{0.8} \operatorname{Pr}^{0.4}
\end{gathered}
$$

\subsection{Boundary Conditions}

The nanofluids volume concentrations $(0.25 \%, 0.5 \%, 0.75 \%$ and $1 \%)$ at $25{ }^{\circ} \mathrm{C}$ base temperature were used for $\mathrm{TiO}_{2}$-water as input fluids. For comparison purposes, water was also employed as a working fluid. CFD studies were carried out with a uniform velocity profile at the inlet and pressure outlet condition were used at the outlet of narrow. Turbulent intensity $(I)$ was specified for an initial guess of turbulent quantities $(k$ and $\varepsilon$ ). The turbulent intensity was estimated for each case based on the following formula:

$$
I=0.16 R e^{-1 / 8}
$$

The walls of the tube were assumed to be perfectly smooth. The constant heat flux condition has been specified on the outside circular tube wall with a value of $3000 \mathrm{~W} / \mathrm{m}^{2}$. Reynolds number was varied from $10^{4}$ to $10^{5}$ at each step of iterations as input data. The friction factor and $\mathrm{Nu}$ were introduced as output data.

\subsection{Grid Independence Test}

Grids independence have been chosen in GAMBIT software for the narrow as 50,000 cells and $1000 \times 50$, subdivisions in the axial, and radial directions, respectively. To find the most suitable size of mesh faces, grid independent testing was performed for the physical model.

In this study, rectangular cells were used to mesh the surfaces of tube wall, but triangular cells were used to mesh the surfaces of the gap as shown in Figure 1b. The grid independence has been checked by using different grid systems and four mesh faces considered 50,000, 40,000, 30,000 and 20,000 for pure water. Friction factor and Nusselt number was determined for all four mesh faces and results were proper. However, any number of mesh faces for these four cases can be used, but in this case, mesh faces with 50,000 have been adopted as the best in terms of the accuracy, as shown in Figure 2. 


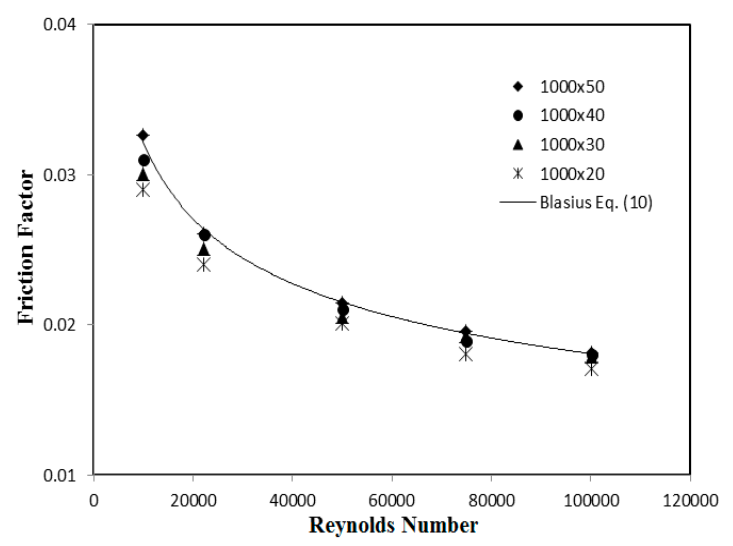

(a)

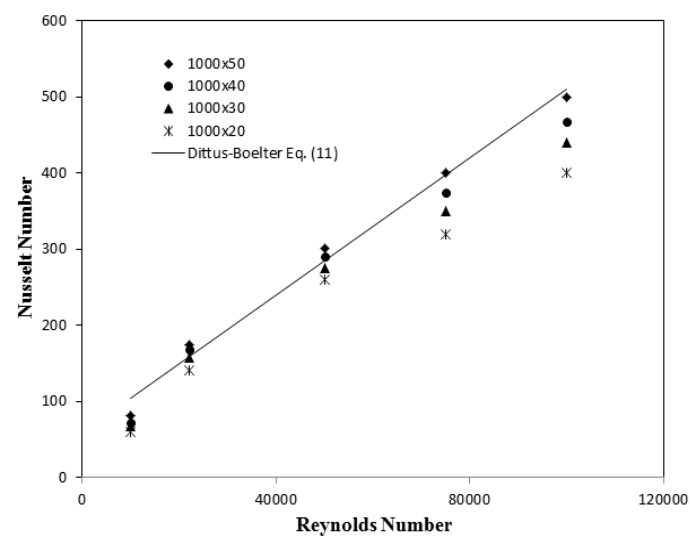

(b)

Figure 2. Meshing grid test. (a) Optimum mesh grid size fodscr friction factor with Reynolds number at $25{ }^{\circ} \mathrm{C}$; (b) optimum mesh grid size of Nusselt number with Reynolds number at $25{ }^{\circ} \mathrm{C}$.

\section{CFD Simulation}

CFD simulations were used FLUENT software with solver strategy. To analyze problems the Gambit software has been used. To make a possible numerical solution of governing equations, single phase conservation equations were solved by control volume approach then converted to a set of algebraic equations. Simulation results were tested by comparing the predicted results of Pak and Cho [7]. FLUENT software was used in CFD analysis in the literature and a detailed description of the mathematical model can be found in the FLUENT User's Guide [26].

The CFD modeling region could be classified into few major steps: Preprocessing stage, the geometry of problem undertaken was constructed as elliptical narrow and computational mesh was generated in GAMBIT. It followed by the physical model, boundary conditions and other parameters appropriate were defined in model's setup and solving stage. All scalar values and velocity components of the problem are calculated at the center of control volume interfaces where the grid schemes are used intensively. Throughout the iterative process accurately monitor of the residuals has been done. When the residuals for all governing equations were lower than $10^{-6}$, all solutions were assumed to be converged.

Finally, the results could be obtained when FLUENT iterations have been led to converged results defined by a set of converged criteria. The friction factor and Nusselt number inside the annulus narrow could be obtained throughout the computational domain in the post-process stage. It has been found that the run of simulation needs $100-250 \mathrm{~s}$ to be steady state at the end of iterations and after that, the solution with graphing all data would be ready.

\section{Results and Discussion}

\subsection{The Effect of Nanofluid Volume Concentrations}

The effect of different volume concentration on friction factor is shown in Figure 3a, at the range of $(0-1 \%)$ nanoparticle volume concentration. The results revealed that $\mathrm{TiO}_{2}$ nanofluid with highest concentration of volume $1 \%$ had the highest friction factor at all Reynolds numbers. The reason of increasing of friction factor with the increasing of concentration of volume of nanofluid is the increasing of fluid viscosity which reduced the moving of fluid; also, validation of friction factor results from the simulation for nanofluid with Blasius equation for water is indicated.

Figure $3 \mathrm{~b}$ shows that Nusselt number is increasing with increasing in volume concentrations of nanofluid because of the high thermal properties of $\mathrm{TiO}_{2}$ that enhancement of heat transfer and hydrodynamic flow. The results are revealed that $\mathrm{TiO}_{2}$ nanofluid with highest concentration of volume $1 \%$ has the highest Nusselt number at all Reynolds numbers. The irregular and random movements of particles increase the energy exchange rates in the fluid with penalty on the wall shear stress and 
consequently enhance the thermal dispersion of the flow. It is also found that the friction factor is decreased while Nusselt number is increased with the increase of Reynolds number. In addition, validation of Nusselt number results from the simulation for nanofluid with the Dittus-Boelter equation for water is showed; similarly, increasing in volume concentrations of nanofluid was led to an increase in Nusselt number and heat transfer enhancement.

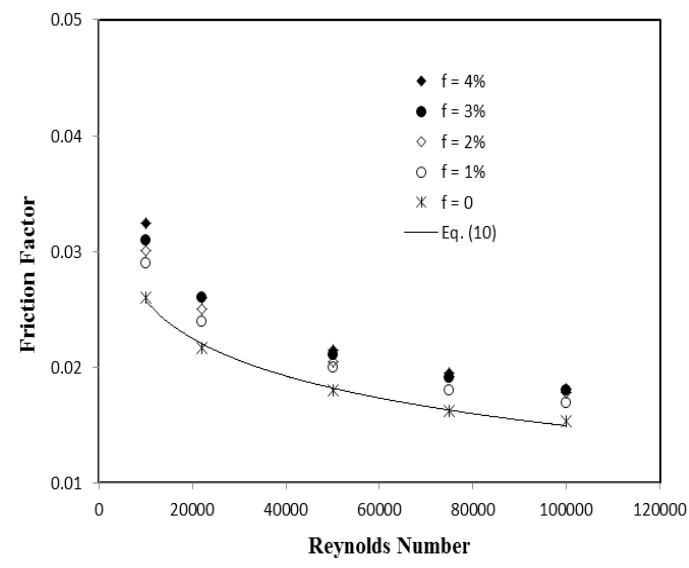

(a)

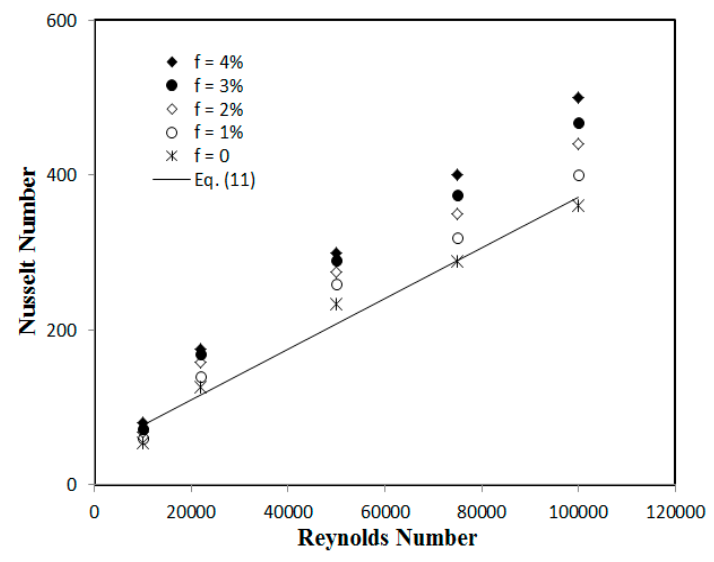

(b)

Figure 3. Effect of volume concentration. (a) Effect of volume concentration of nanofluid on fiction factor; (b) effect of nanofluid volume concentration on heat transfer enhancement.

\subsection{The Effect of Nanofluid Size Diameter}

The effect of different nanoparticle size diameters of $\mathrm{TiO}_{2}$-water nanofluid on the friction factor and Nusselt number with different Reynolds numbers was examined in this section. The ranges of nanoparticle diameter are varied from $27 \mathrm{~nm}$ to $50 \mathrm{~nm}$ with $1 \%$ concentration of $\mathrm{TiO}_{2}$ nanofluid. Figure 4a shows the effect of nanoparticle size diameters of $\mathrm{TiO}_{2}$ on the friction factor with different Reynolds numbers. It appears that friction factor has minor changes when nanoparticle diameters of $\mathrm{TiO}_{2}$ nanofluid are varied. As shown in this figure the nanofluid with $27 \mathrm{~nm}$ nanoparticle size diameter has the highest friction factor, whereas, the nanoparticle with a diameter of $50 \mathrm{~nm}$ has the lowest friction factor. Figure $4 \mathrm{~b}$ revealed that Nusselt number has lower value with higher particle size diameter of $\mathrm{TiO}_{2}$ nanofluid. It may be the high specific surface area of the nanoparticle is the reason for the effect of size diameter; with the heat transfer being dependent on the surface area.

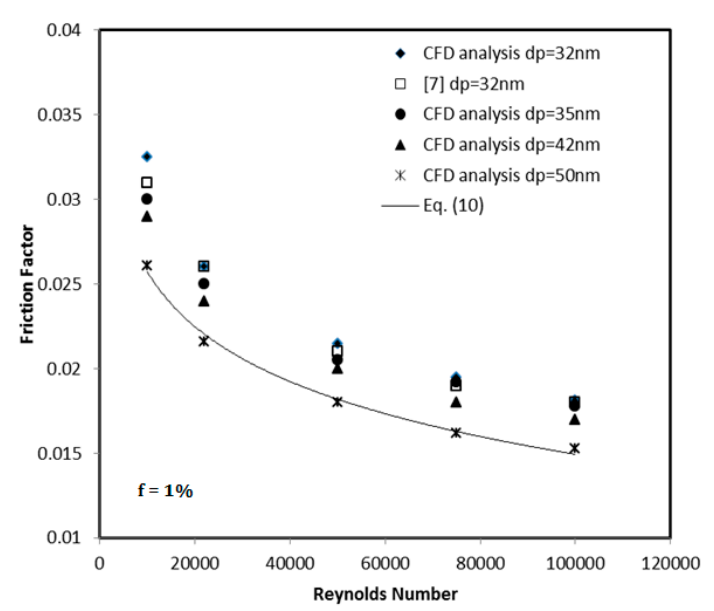

(a)

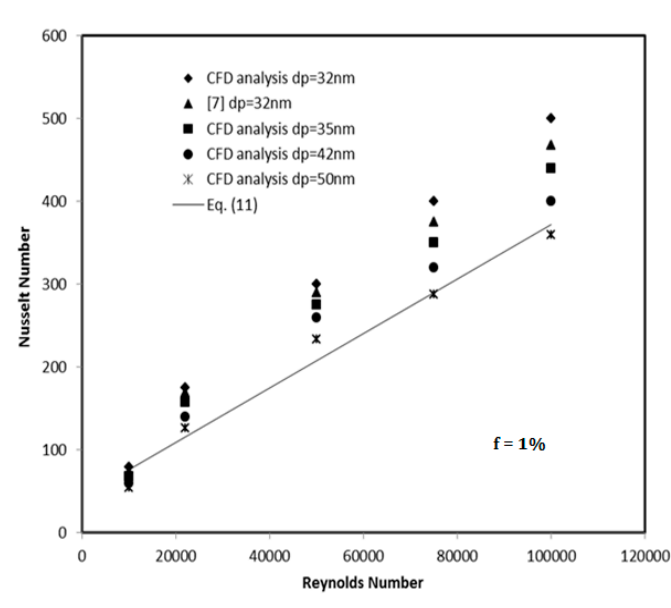

(b)

Figure 4. The effect of particles size diameter. (a) The effect of particle size diameter on friction factor with Reynolds number; (b) the effect of particles size diameter on Nusselt number with Reynolds number. 


\subsection{Comparison CFD Results with Experimental Data}

This section analyzes the comparison between CFD data and experimental data for $\mathrm{TiO}_{2}$-water nanofluid with particle size is $27 \mathrm{~nm}$ and the base temperature is $25^{\circ} \mathrm{C}$. Figure 5 shows the CFD analysis of friction factor versus Reynolds number compared with Pak and Cho [7] experimental data. There is the same behavior and good agreement with a deviation of $2 \%$. On the other hand, Nusselt number versus Reynolds number compared with Pak and Cho [7] experimental data as shown in Figure 6. There is good agreement with a deviation of $1.4 \%$. Results show that the annulus tubes have enhancement of heat transfer and hydrodynamic flow more than the circular tube.

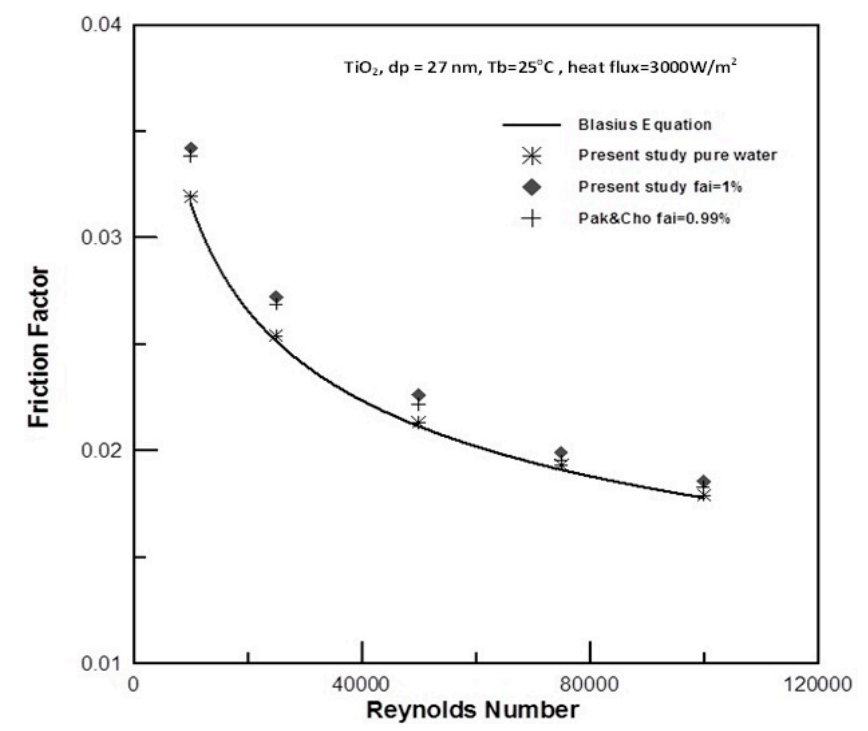

Figure 5. Comparison CFD results of friction factor with Pak and Cho experimental data [7].

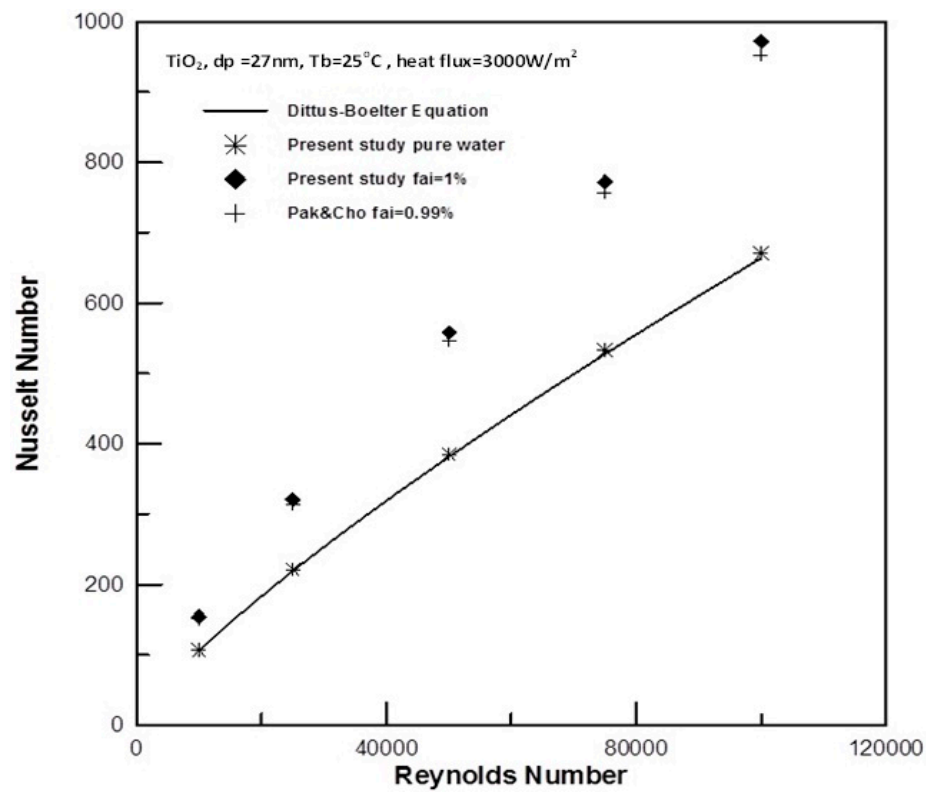

Figure 6. Comparison CFD results of $N u$ with Pak and Cho experimental data [7].

\section{Conclusions}

In this paper, forced convection heat transfer through an elliptical inside a circular tube under turbulent flow by numerical simulation, with uniform heat flux boundary condition around circular tube has been studied. The heat transfer enhancement resulting from various parameters such as nanoparticle concentration of volume and Reynolds number is reported. The finite volume methods 
have been used to solve the governing equations with certain assumptions and appropriate boundary conditions. The Nusselt number, friction factor was obtained through the numerical simulation.

The study is concluded as follows:

- The enhancement of friction factor and Nusselt numbers are $14 \%$ and $19 \%$ for enhanced tube than that of the circular tube at all Reynolds numbers.

- The concentration of volume $(1 \%)$ of $\mathrm{TiO}_{2}$ nanofluid has the highest Nusselt number and friction factor values, followed by $(0.75 \%, 0.5 \%$, and $0.25 \%)$ finally pure water has the lowest values of them.

- There is a good agreement between simulation results and experimental data of Pak and Cho [7] with a deviation of $2 \%$ and $1.4 \%$ for $N u$ and friction factor respectively.

Author Contributions: A.M.H. and Q.K.J. conceived and designed the experiments; Q.K.J. performed the experiments; S.H.D. and A.M.H. analyzed the data; Q.K.J. contributed reagents/materials/analysis tools; S.H.D. wrote the paper.

Acknowledgments: The authors would like to thank University Malaysia Pahang for supporting the work by allowing using computer lab.

Conflicts of Interest: The authors declare no conflicts of interest.

\section{Nomenclatures}

C specific heat capacity $\left[\mathrm{W} /\left(\mathrm{kg} \cdot{ }^{\circ} \mathrm{C}\right)\right]$

$D$ diameter $[\mathrm{m}]$

E energy [W]

$f$ friction factor

$h \quad$ convection heat transfer coefficient $\left[\mathrm{W} /\left(\mathrm{m}^{2} \cdot{ }^{\circ} \mathrm{C}\right)\right]$

$k \quad$ thermal conductivity $\left[\mathrm{W} /\left(\mathrm{m} \cdot{ }^{\circ} \mathrm{C}\right)\right]$

$\mathrm{Nu} \quad$ Nusselt Number $\left[h t c \cdot D / K_{n f}\right]$

$P \quad$ Pressure $\left[\mathrm{N} / \mathrm{m}^{2}\right]$

$\operatorname{Pr} \quad$ Prandtle Number $\left[C \cdot \mu / K_{n f}\right]$

Re Renolds Number $\left[\rho_{n f} \cdot D_{h} \cdot u / K_{n f}\right]$

$u$ Velocity $[\mathrm{m} / \mathrm{s}]$

$\mu \quad$ Viscosity $\left[\mathrm{N} \cdot \mathrm{s} / \mathrm{m}^{2}\right]$

$\rho \quad$ Density $\left[\mathrm{kg} / \mathrm{m}^{3}\right]$

$\tau \quad$ Shear stress $\left[\mathrm{N} / \mathrm{m}^{2}\right]$

$\varphi \quad$ Volume concentration

\section{Subscripts}

$f \quad$ liquid phases

$p \quad$ solid particle

nf nanofluid

$h \quad$ hydraulic

\section{References}

1. Das, S.K.; Choi, S.U.; Yu, W.; Pradeep, T. Nanofluids: Science and Technology; John Wiley \& Sons, Inc.: Hoboken, NJ, USA, 2007.

2. Moghari, R.M. Two phase mixed convection $\mathrm{Al}_{2} \mathrm{O}_{3}$-water nanofluid flow in an elliptical tube. Int. J. Multiph. Flow 2011, 3, 585-595. [CrossRef]

3. Hussein, A.M.; Bakar, R.A.; Kadirgama, K.; Sharma, K.V. The effect of nanofluid volume concentration on heat transfer and friction factor inside a horizontal tube. J. Nanomater. 2013, 2013, 1-12. [CrossRef]

4. Puli, U.; Rajvanshi, A.K. An image analysis technique for determination of void fraction in sub cooled flow boiling of water in horizontal elliptical tube at high pressures. Int. J. Heat Fluid Flow 2012, 38, 180-189. [CrossRef] 
5. Hussein, A.M.; Bakar, R.A.; Kadirgama, K.; Sharma, K.V. Heat transfer enhancement with elliptical tube under turbulent flow $\mathrm{TiO}_{2}$-water nanofluid. Therm. Sci. 2016, 20, 89-97. [CrossRef]

6. Heris, S.Z. Convective Heat Transfer of a $\mathrm{Cu} /$ Water Nanofluid Flowing through a Circular Tube. Exp. Heat Transf. 2009, 22, 217-227. [CrossRef]

7. Pak, B.C.; Cho, Y.I. Hydrodynamic and Heat Transfer Study of Dispersed Fluids with Submicron Metallic Oxide Particles. Exp. Heat Transf. 1998, 11, 151-171. [CrossRef]

8. Sharma, K.V.; Sarma, P.K.; Azmi, W.H.; Mamat, R.; Kadirgama, K. Correlations to Predict Friction and Forced Convection Heat Transfer Coefficients of Water Based Nanofluids for Turbulent Flow in a Tube. IJMNTFTP 2010, 3, 1-25.

9. Kumar, P. A CFD Study of Heat Transfer Enhancement in Pipe Flow with $\mathrm{Al}_{2} \mathrm{O}_{3}$ Nanofluid. Eng. Tech. 2011, 57, 746-750.

10. Bianco, V. Numerical Investigation on Nanofluids Turbulent Convection Heat Transfer inside a Circular Tube. Int. J. Therm. Sci. 2011, 50, 341-349. [CrossRef]

11. Sundar, L.S.; Sharma, K.V. Turbulent Heat Transfer and Friction Factor of $\mathrm{Al}_{2} \mathrm{O}_{3}$ Nanofluid in Circular Tube with Twisted Tape Inserts. Int. J. Heat Mass Transf. 2010, 53, 1409-1416. [CrossRef]

12. Durmus, A.; Durmus, A.; Esen, M. Investigation of heat transfer and pressure drop in a concentric heat exchanger with snail entrance. Appl. Therm. Eng. 2002, 22, 321-332. [CrossRef]

13. Hussein, A.M.; Bakar, R.A.; Kadirgama, K.; Sharma, K.V. Study of forced convection nanofluid heat transfer in the automotive cooling system. Case Stud. Therm. Eng. 2014, 2, 50-61. [CrossRef]

14. Hussein, A.M.; Bakar, R.A.; Kadirgama, K.; Sharma, K.V. Heat transfer enhancement by using nanofluids in an automotive cooling system. Int. Commun. Heat Mass Transf. 2014, 53, 195-202. [CrossRef]

15. Manglik, R.M.; Bergles, A.E. Heat transfer and pressure drop correlations for twisted-tape inserts in isothermal tubes: Part II-Transition and turbulent flows. J. Heat Transf. 1992, 202, 99-106. [CrossRef]

16. Sarma, P.K.; Subramanyam, T.; Kishore, P.S.; Dharma, R.V.; Kakac, S. Laminar convective heat transfer with twisted tape inserts in a tube. Int. J. Therm. Sci. 2003, 42, 821-828. [CrossRef]

17. Duangthongsuk, W.; Wongwises, S. An Experimental Study on the Heat Transfer Performance and Pressure Drop of $\mathrm{TiO}_{2}$-Water Nanofluids Flowing under a Turbulent Flow Regime. Int. J. Heat Mass Transf. 2010, 53, 334-344. [CrossRef]

18. Prajapati, O.S. Effect of $\mathrm{Al}_{2} \mathrm{O}_{3}$-Water Nanofluids in Convective Heat Transfer. Int. J. Nano Sci. 2012, 1, 1-4. [CrossRef]

19. Kittur, B.G. On the Forced Convective Flow between Two Corrugated Cylinders. Adv. Theor. Appl. Mech. 2010, 3, 491-506.

20. Bozorgan, N.; Mafi, M.; Bozorgan, N. Performance Evaluation of $\mathrm{Al}_{2} \mathrm{O}_{3}$ /Water Nanofluid as Coolant in a Double-Tube Heat Exchanger Flowing under a Turbulent Flow Regime. Adv. Mech. Eng. 2012, 4, 891382. [CrossRef]

21. Demir, H.; Dalkilic, A.S.; Kürekci, N.A.; Duangthongsuk, W.; Wongwises, S. Numerical investigation on the single phase forced convection heat transfer characteristics of $\mathrm{TiO}_{2}$ nanofluids in a double-tube counter flow heat exchanger. Int. Commun. Heat Mass Transf. 2011, 38, 218-228. [CrossRef]

22. Luciu, R.S.; Mateescu, T.; Cotorobai, V.; Mare, T. Nusselt number and convection heat transfer coefficient for a coaxial heat exchanger using $\mathrm{Al}_{2} \mathrm{O}_{3}$-water $\mathrm{pH}=5$ nanofluid. Bul. Inst. Polit. Iasi 2009, 55, 71-80.

23. Mohsen, S.; Rashidi, M.M.; Ganji, D.D. Effect of non-uniform magnetic field on forced convection heat transfer of $\mathrm{Fe}_{3} \mathrm{O}_{4}$-water nanofluid. Comput. Methods Appl. Mech. Eng. 2015, 294, 299-312.

24. Rashidi, M.M.; Abelman, S.; Mehr, N.F. Entropy generation in steady MHD flow due to a rotating porous disk in a nanofluid. Int. J. Heat Mass Transf. 2013, 62, 515-525. [CrossRef]

25. Hussein, A.M. Thermal performance and thermal properties of hybrid nanofluid laminar flow in a double pipe heat exchanger. Exp. Therm. Fluid Sci. 2017, 88, 37-45. [CrossRef]

26. FLUENT 6.3 User's Guide. Available online: https://www.sharcnet.ca/Software/Fluent6/html/ug/main pre.htm (accessed on 23 September 2018).

(C) 2018 by the authors. Licensee MDPI, Basel, Switzerland. This article is an open access article distributed under the terms and conditions of the Creative Commons Attribution (CC BY) license (http:/ / creativecommons.org/licenses/by/4.0/). 